\title{
Too early to execute the strategic scenario planning: hyperbolic discounting and psychological biases of Indonesian SMEs' managers
}

Rayenda Brahmana, Widyana Verawaty Siregar and Arnawan Hsb

\author{
Rayenda Brahmana is \\ based at the School of \\ Management, Universiti \\ Sains Malaysia, Minden, \\ Malaysia. \\ Widyana Verawaty Siregar \\ is based at the Faculty of \\ Economics, Universitas \\ Malikussaleh, \\ Lhoseumawe, Indonesia. \\ Arnawan Hsb is based at \\ the Faculty of Engineering, \\ Universitas Malikussaleh, \\ Lhoseumawe, Indonesia.
}

\begin{abstract}
1. Introduction
To survive in a turbulent environment, the firm manager develops a strategy by assessing the environment which includes scenario planning to tackle unpredictable events based on information gathering, analysis, and planning activity (Wright, 2000). This scenario planning assists the organization to anticipate anomalous conditions, understand the risk and awareness of alternate future possibilities. Indeed scenario planning must follow the utility function and economics motive. However, because building a strategy is fully subjective in nature, the role of psychology might influence the strategic decision making process (Schwartz, 1996); an issue which is commonly overlooked by academicians and practitioners.

The standard tenet in decision science is agents (or in our case firm managers) are assumed to be time-consistent following their utility function. This assumption addresses that a contrast time preference such as short run and long run never arises; or so-called exponential discounting. However, a growing body of literature has challenged this traditional view and allows firm managers to be time inconsistent by modeling their discount function as hyperbolic. This is the contrasting view that this study will enrich, where firm managers do not always follow their utility function in making strategic decisions.
\end{abstract}

Firm managers with hyperbolic discount[1] functions demonstrate a high degree of discounting in the short run but a relatively low degree of discounting in the long run (Rubinstein, 2003). Therefore, hyperbolic firm managers are likely to delay tasks with immediate costs and delayed benefits, whereas they would choose to perform the same task if both costs and benefits were to occur in the future.

Relating back to business strategy formulation, firm managers are assumed not to follow their personal preferences, be rational, and time-consistent in making decision. In terms of scenario planning of business strategy formulation, its strength lies in the value of interpreting the environment (Raspin and Terjesen, 2007). The well-formulated scenarios assist managers to develop their sense-making skills (Weick, 1995) by framing and reframing the business environment. As it is based on the intuition of managers, the role of psychology might affect the decision making; a situation that has implication for organization performance.

Our interest in this study is to revisit the psychological influence on the early implementation of business strategy scenario planning moderated by hyperbolic discounting. Instead of confirming the previous literature about strategic management, we choose to focus on finding another explanation beyond decision making. We do believe the existing literature empirically argue the decision making under the utility function circumstance. Meanwhile, in the real world, decision making does not always follow the rational assumption. Mainly in the small and medium enterprises (hereafter SME), whereas the literature suggest they are more irrational in crafting strategy compared to larger companies (see Gagnon et al., 2000; 